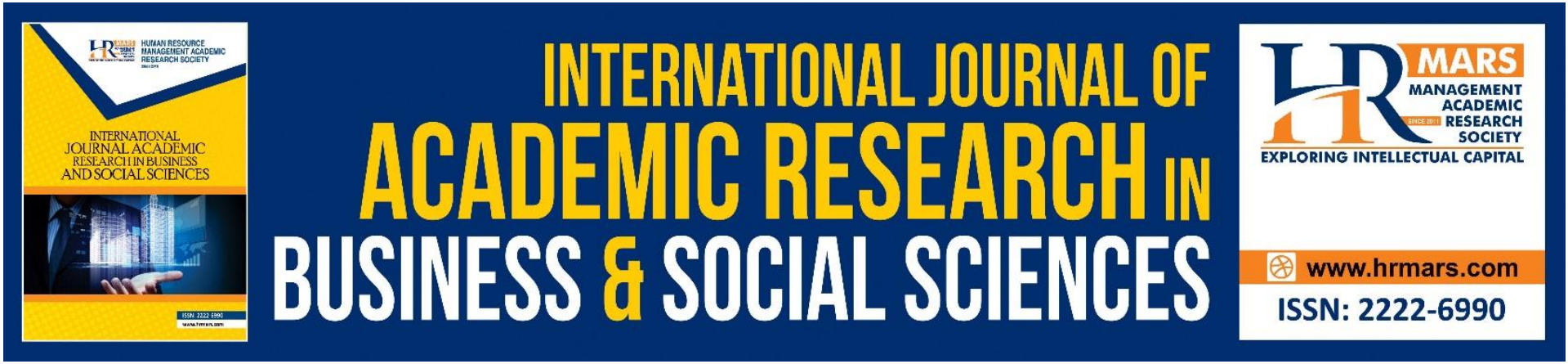

\title{
Critical Factors for Malaysian Young Consumers' Buying Decision on Green Products
}

Khairul Anuar Bin Rusli, Annie Yong Ing Ing \& Loh Mei Ting

To Link this Article: http://dx.doi.org/10.6007/IJARBSS/v12-i1/10429 DOI:10.6007/IJARBSS/v12-i1/10429

Received: 14 November 2021, Revised: 19 December 2021, Accepted: 27 December 2021

Published Online: 21 January 2022

In-Text Citation: (Rusli et al., 2022)

To Cite this Article: Rusli, K. A. Bin, Ing, A. Y. I., \& Ting, L. M. (2022). Critical Factors for Malaysian Young Consumers' Buying Decision on Green Products. International Journal of Academic Research in Business and Social Sciences, 12(1), 1060-1075.

Copyright: @ 2022 The Author(s)

Published by Human Resource Management Academic Research Society (www.hrmars.com)

This article is published under the Creative Commons Attribution (CC BY 4.0) license. Anyone may reproduce, distribute, translate and create derivative works of this article (for both commercial and non0-commercial purposes), subject to full attribution to the original publication and authors. The full terms of this license may be seen at: http://creativecommons.org/licences/by/4.0/legalcode

Vol. 12, No. 1, 2022, Pg. 1060 - 1075

Full Terms \& Conditions of access and use can be found at http://hrmars.com/index.php/pages/detail/publication-ethics 


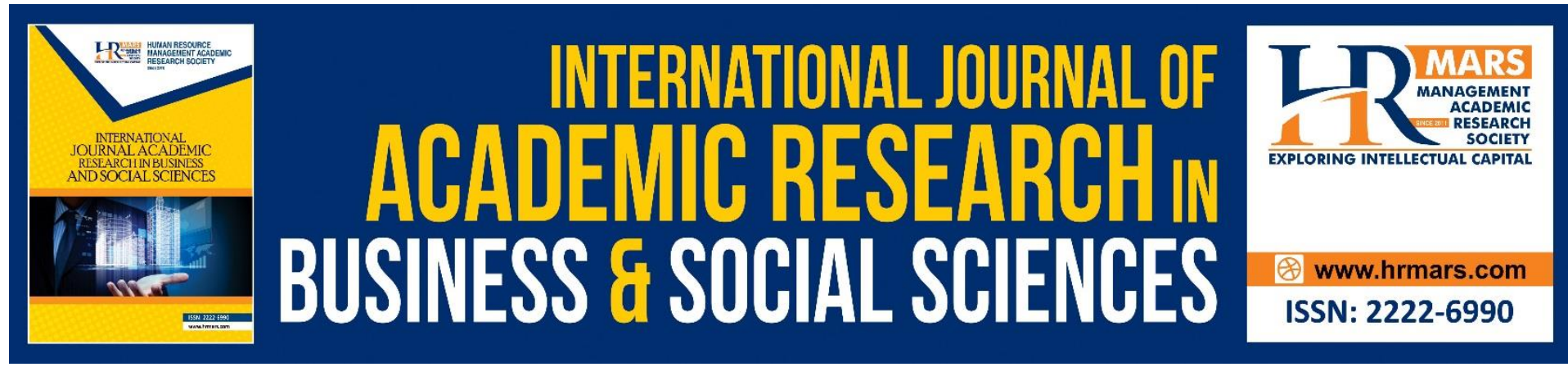

\title{
Critical Factors for Malaysian Young Consumers' Buying Decision on Green Products
}

\author{
Khairul Anuar Bin Rusli, Annie Yong Ing Ing \& Loh Mei Ting \\ Faculty of Accountancy and Management, Universiti Tunku Abdul Rahman (UTAR) Sg Long \\ Campus, 43000 Kajang, Selangor \\ Corresponding author: khairular@utar.edu.my
}

\begin{abstract}
The development of advanced technology was growing rapidly nowadays, it brings both positive or negative impact and changes on environment. Since people have a good view and mind-set on environmental protection, hence people are encouraged to enhance the health of environment during enjoying the convenience provided by technology. This research is aimed to investigate the factors that influence Malaysia's young consumers buying decision on green products. 384 young consumers aged between 18 and 30 years old are the targeted respondents in this research study. Questionnaires were distributed in Klang Valley in Malaysia. Abased on the data analysis, it shows that all independent variables have significant relationship with the dependent variable. The findings of this research contributed better insight and businesses for those who will face a lot of challenges in promoting and convincing young consumers to purchase green products. Through this gathered information, marketers able to know and understand how to effectively attract the young consumers to purchase green products by developing various strategies.
\end{abstract}

Keywords: Young Consumers, Green Products, Buying Decision

\section{Introduction}

Environmental problems are the hottest topic nowadays that have captured attentions of the public around the world. Due to the increasing global unsustainable consumption levels, the serious environmental concerns were happened such as greenhouse effect, water pollution, land pollution, air pollution and global warning. Therefore, the environment issues have greater impact on consumer's making decisions when consuming the products. The customers today more concerned about environmental changes and changing their behaviors (Uddin \& Khan, 2016; Lian \& Yoong, 2019). Previous studies show that the young adults had many positive views towards green products such as energy efficient appliances, cosmetics without tested on animals, hybrid vehicles and recyclable packaging (Hessami \& Yousefi, 2013; Varshneva et al., 2017; Nguyen et al., 2018). Meanwhile, green technologies and eco-friendly products able to expand sustainable economy if environmental performance of the country is improved (Joshi \& Rahman, 2015).

Besides, the government of Malaysia and Non-governmental organisations have reached consensus on strengthen Malaysia's sustainable development. Thus, the corporate 
community from Malaysia had carried out some campaigns hence it can reduce the usage of plastic bags and promote green lifestyle. For instance, those hypermarkets like Aeon, Tesco and NSK held "No Plastic Bag Day" campaign every Saturday or Sunday. The consumers have to bring their own recycle bag during grocery shopping. Besides, Sime Darby and Digi had joined green campaign including Plant a Tree Program and Mangrove-Saving Project respectively. Malaysia community also involved in a green awareness event which called Earth Hour to encourage public reduce impact on environment (Noor et al., 2012).

Other than that, Malaysia aimed to increase recycling quota from $5 \%$ to $22 \%$ by 2020 . For example, the government planned to raise awareness of $3 R$ (reuse, reduction and recycling) to the public (Rezai, et al., 2013). In addition, the use of green products can minimize the pollution because they are natural resources while non-biodegradable products like plastic straw are not recyclable, it may damage the environment. Hence, Malaysian government started taken initiative to ban plastic straw and polystyrene food packaging in Kuala Lumpur, Putrajaya and Labuan. For an illustration, the biodegradable straws instead of plastic straws will be used in food court, restaurant and hawker stalls or the consumers drinking without straws (Kadir et al., 2018).

\section{Problem Statement}

In the past ten years, the consumption of goods and services by consumers keep increasing, however this cause natural resources depleting and serious damage to environment. Many other countries begin to reduce the harmful effects of their business activities on the environment (Dagher \& Ithani, 2014) Sustainable development of Malaysia also encouraged the green consumption and ecological innovation of the eco- friendly products (Joshi \& Rahman, 2015). Based on the figure 1.1, it portrays that emission of pollutant is the one of the biggest environmental issue in Malaysia. The highest percentage of source that affect emission is $70.4 \%$ from motor vehicles, followed by $24.5 \%$ from power plant. According to Chong, et al. (2019), due to the reason that the economics of Malaysia is growing rapidly through the process of industrialization and urbanization in the past 40 years, therefore their energy consumption keep increasing and this cause the carbon (CO2) emissions happened. In fact, it is undeniable that the scale of coal-fired power in Malaysia is still growing every year while other countries starting to shut down power plants to reduce the growth of $\mathrm{CO} 2$ emissions. This happened cause people in Malaysia faced many health diseases like eye irritation, skin irritation, throat irritation etc. are keep growing every year.

Figure 1.1: Percentage emission of pollutants to the atmosphere by source, Malaysia

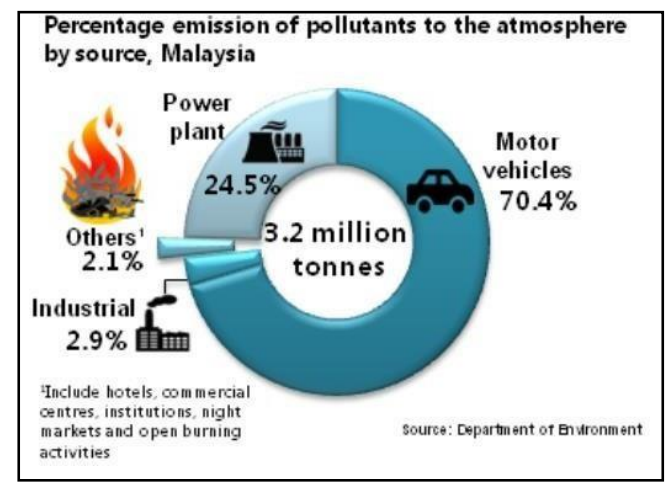


Source: Current Population Estimates in Malaysia, 2020. (2020) Moreover, promoting green behaviour is regarded as a basic part of ecological education in Malaysia. According to the investigation from Global Green Economy Index (GGEI), Malaysia is not a best performing country in terms of climate change, environment and overall efficiency. Malaysia is facing serious environmental challenges. There is a research study indicated that Malaysia generates 3, 8000 tons of consumer environment waste everyday regardless environmental cost. Based on the statistic, there are $9 \%$ of environmental waste was recycled, $12 \%$ of waste had incinerated and $79 \%$ of waste had landfilled in Malaysia, this will harm people's health and environmental issues occurred. According to Uddin, and Khan (2016), it revealed that most of the youths are interested in purchasing green products. However, most of the educated young consumer still have low awareness of green products in Malaysia (Kadir et al. 2018). It shows that young consumers do not always prefer green products during shopping even though they are concern with the environmental issues (Yadav, \& Pathak, 2017). This cause the response of young consumers towards green products is not reliable. It is important to promote GPB for young generation by creating youth's green awareness. Due to the reason that environmental protection is the responsibilities of consumers especially youths. Therefore, this study carried out to examine the factors that influence Malaysian young consumer' buying decision on green products.

\section{Literature Review \\ Theory of Planned Behaviour (TPB)}

Based on the study of Liobikienè et al (2016), main dependent variable of TPB is consumer intention which is an evidence of a person's ability to act in a certain way. There are four factors of TPB including subjective norms and perceive, attitude towards the behaviour and perceived behavioural control. Besides, this study explained that higher prices and confidence in green products affecting the action gap between intentions and behaviour happened.

TPB is a framework for best understanding human behaviour in a wide range of areas and it is important in the environmental psychology. It was applied to measure the impact on green purchasing intentions and behaviour. Yadav, and Pathak (2017) explained that subjective norm, attitude towards the behaviour and perceived behavioural control are led to form the behavioural intentions and towards the behaviour. This study revealed that attitude, subjective norm and perceived behavioural control play an important role in GPB. 
Figure 2.1: Theory of Planned Behaviour

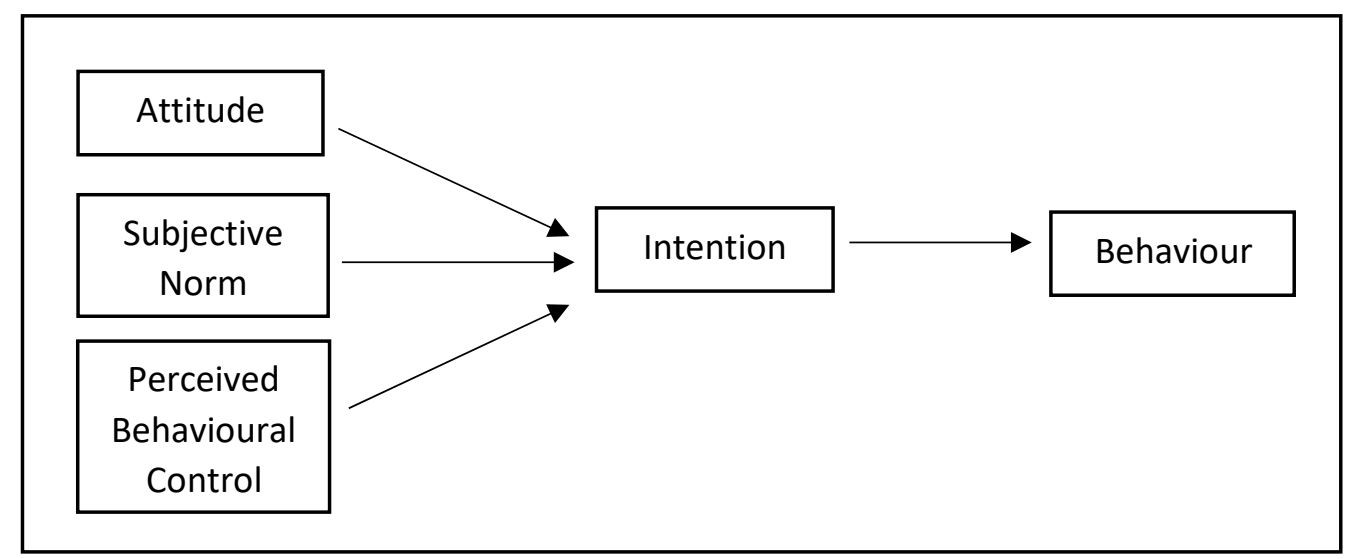

Adapted from: Yadav, \& Pathak (2017). Determinants of consumers' GPB in a developing nation: Applying and extending the theory of planned behaviour.

\section{Buying Decision on Green Products (GPB)}

According to Dagher, and Itani (2014), GPB refers to the consumption of eco-friendly products that are sensitive, recyclable and beneficial to the environment. Green consumers tend to change the marketplace, as they realized that their buying behaviour is one of the impacts on the environment. Therefore, the environment issues now been strengthening and becoming top priority in the world, this may lead the young generation to increase GPB. This behaviour is very important for the environment and consumers. Furthermore, GPB including the efforts to save the energy and stop purchasing products with non-recyclable packaging. At the same time, the products that consumers purchase and consume are made from recyclable materials are considered as GPB. Zand Hessami, and Yousefi (2013) explained that green products are biodegradable and recyclable products. Other than the products are manufactured from organic production, their packaging are minimal in design.

\section{Environmental Attitude (EA)}

According to Nguyen et al (2018), EA is the important for understanding environmentally friendly behaviour. Besides, the attitude variables were discussed including New Environmental Paradigm, environmental issues and particular attitudes indicating judgements about environmental behaviour and green products. In a recent research study, it was found that EA is one of the factor that will influence GPB. EA, in this study is defined as the cognitive judgment of environmental protection value. This paper was conducted in Hong Kong to investigate EA in GPB. A survey was conducted among 5965 respondents where 2930 of males and 3035 of females are came from 48 high schools.

In India, a research was conducted to examine on the impact of EA on GPB. According to this journal, a sample was conducted among 161 respondents that come from high school and senior secondary school where they aged between 15-18 years old. The questionnaires are written in English which known as International language due to the respondents' study at English secondary school in India. Meanwhile, this study shows that young generation are more concerned about environmental issues than older generation. Uddin, and Khan (2016) stated that consumer's EA play an important role on sustainable consumption. The EA of young generation is representing a healthy environment in the future. Through results of the findings, it justified that there is a positive relationship between EA and GPB. 


\section{Social Influence (SI)}

According to this journal, a research was conducted in Lebanon to investigate the impact of $\mathrm{SI}$ on GPB. The questionnaires were successfully collected from 101 respondents through emails which were Lebanese consumers who have independent purchasing power. Based on the findings, SI can be observed at peer pressure, standard compliant and other factors. GPB was influenced by SI that led to share the information through the social media such as email, blog, Instagram, Twitter, Facebook and YouTube. This hypothesis was accepted that SI has a positive impact on GPB. In short, it was justified that SI was directly affecting GPB (Dagher, \& Itani, 2012).

Nguyen, et al (2018) explained that SI also known as subjective social norms. It was defined as the consumers often seek opinion and support from others who are important to them as their reference for green purchase decision making. As an illustration, young consumers nowadays consider about the opinions that given by friends, parents and professors when conducting environmentally friendly behaviour. This research was conducted in Vietnam to investigate the relationship between SI and young generation's GPB. Based on the findings, a quantitative study was conducted among 262 respondents where they aged between 18 to 20 years old. In a result of analysis, this hypothesis proven that SI has positive impact on GPB.

A research study conducted by Hessami, et al (2013), SI is the impact of the social environment on consumers' GPB. For example, the action performed by young generation are how much knowledge about green products they know through their family, how much the field of green products they discussed through their friends and how much they are sharing information about green products with family. According to this journal, this study was carried out to investigate the social impact on youth's GPB. A sample of 24 respondents was conducted among experienced experts and

professors through DEMATEL method. In brief, $\mathrm{SI}$ is positive factors on affecting young generation's GPB.

Liobikienè, et al (2016) stated that subjective norms can be understood as perceived social forces to perform the specific behaviour. Those individuals who feel morally liable for others by purchasing green products and how important for them to have good social image. Based on the analysis, SI has positive impact on GPB among young generation.

According to Varshneya et al (2017), this study research conducted in India among 160 respondents that aged between 20 to 40 years old. The questionnaires were successfully collected through online survey from the young adult consumers. In this journal, $\mathrm{SI}$ is when the people were affected by their surroundings or society, the changes of their own feelings, thoughts and behaviours will be happened. It is a positive factor in behavioural research because most of the people seek for the social evidence before people trying a new product. This study results justified that SI has a positive relationship between SI and GPB.

\section{Perceived Environmental Knowledge (PEK)}

Based on the research study, this study was conducted in India to investigate the influence on PEK on GPB. According to Jaiswal \& Kant (2018), PEK is for understanding the issues that related with sustainability like water pollution, air pollution, usage of energy, recycling and their impact on natural environment. It was classified with abstract and concrete knowledge to determine the action of environment. There is a quantitative method was applied among 
351 respondents where there are 188 of male and 163 of female. The questionnaires were written in Indian English and collected successfully from the respondents. This study was concluded that the hypothesis was accepted where PEK has positive relationship with GPB.

In Europe Union, a research study was conducted to determine the impact of PEK on GPB. A quantitative survey was conducted among 28 respondents while qualitative method where interview was carried out among the respondents aged below 15 years old with their native language. Based on the study, Liobikienè, et al (2016) indicated that people always think that knowledge of environmental is the motivation or support for GPB. Therefore, the consumers who are full of knowledge about environmental issues and the use of green products might be more positive attitude towards green products. This hypothesis proven that there is a positive relationship between PEK and GPB.

Nguyen, et al (2018) interpreted that environmental knowledge is the main focus of education of environmental and consumers' green consumption. Consumers' knowledge of the environment is the knowledge about environmental issues, ecosystems, consequences of human action on environment and green products. A quantitative method was applied among 262 respondents where they aged between 18 to 20 years old. Based on the findings of the study, this hypothesis is accepted where young generation's environmental knowledge has positive relationship with GPB. In brief, it is undeniable that PEK had directly influenced behaviour to make purchase on green products.

In addition, there is a study conducted in Egypt to examine PEK on gender differences in GPB. The questionnaires were distributed among 1093 respondents where 516 are male and 577 are females. The surveys was collected successfully from the university students which classified into seniors, juniors, sophomore, freshman and graduate students. According to Mostafa (2007) and Noor et al. (2012), environmental knowledge defined as common knowledge that about the concepts, facts and the relationship of the physical environment and its ecosystems. It also including consumers' understanding of the environment that led to environmental impacts by realizing the responsibility of sustainable development. In conclusion, PEK is positive factors that influencing consumers' GPB.

\section{Perceived Consumer Effectiveness (PCE)}

According to Uddin \& Khan (2016), a research study was conducted in India to analyse the influence of perceived consumer effectiveness on GPB. A quantitative method was carried out among 390 respondents through the survey. The questionnaires were collected from five main cities which are Indore, Bhopal, Gwalior, Jabalpur and Rewa for research purpose. Based on the study, it indicated that PCE defined as believe of an individual that his or her actions are useful in solving the problems. Besides, PCE is used to measure the element of personality variable to estimate the environmental issues and the responsibility of ecological consumption. As the results, it justified that PCE able to influence consumers' purchasing decision. The hypothesis is accepted where there is a relationship between PCE and GPB.

This research was conducted in India to study the relationship that PCE influencing on consumers' GPB. The questionnaires were carried out with Indian English as India's official language. The quantitative study was applied among 351 respondents where there are 188 of male and 163 of female. According to the journal, PCE is one of the important 
measurements of GPB. It is used to determine whether the individual take efforts on solving the environmental issues. PCE is the perception of consumers which their actions able to solve the environmental problems facing and ecological problems. This hypothesis proven that PCE had directly affecting purchase behaviour for green products (Jaiswal \& Kant, 2018).

In the recent study, it was found that PCE is one of the impacts on GPB. This research study was conducted by Kim, and Choi (2005), PCE refer as make evaluation yourself in a problem, which is different from the attitude that reflects on the evaluation of the problems. It was identified by the knowledge and experiences as well as changing according to individual's knowledge and experiences.

Figure 2.2: Research Framework for this study

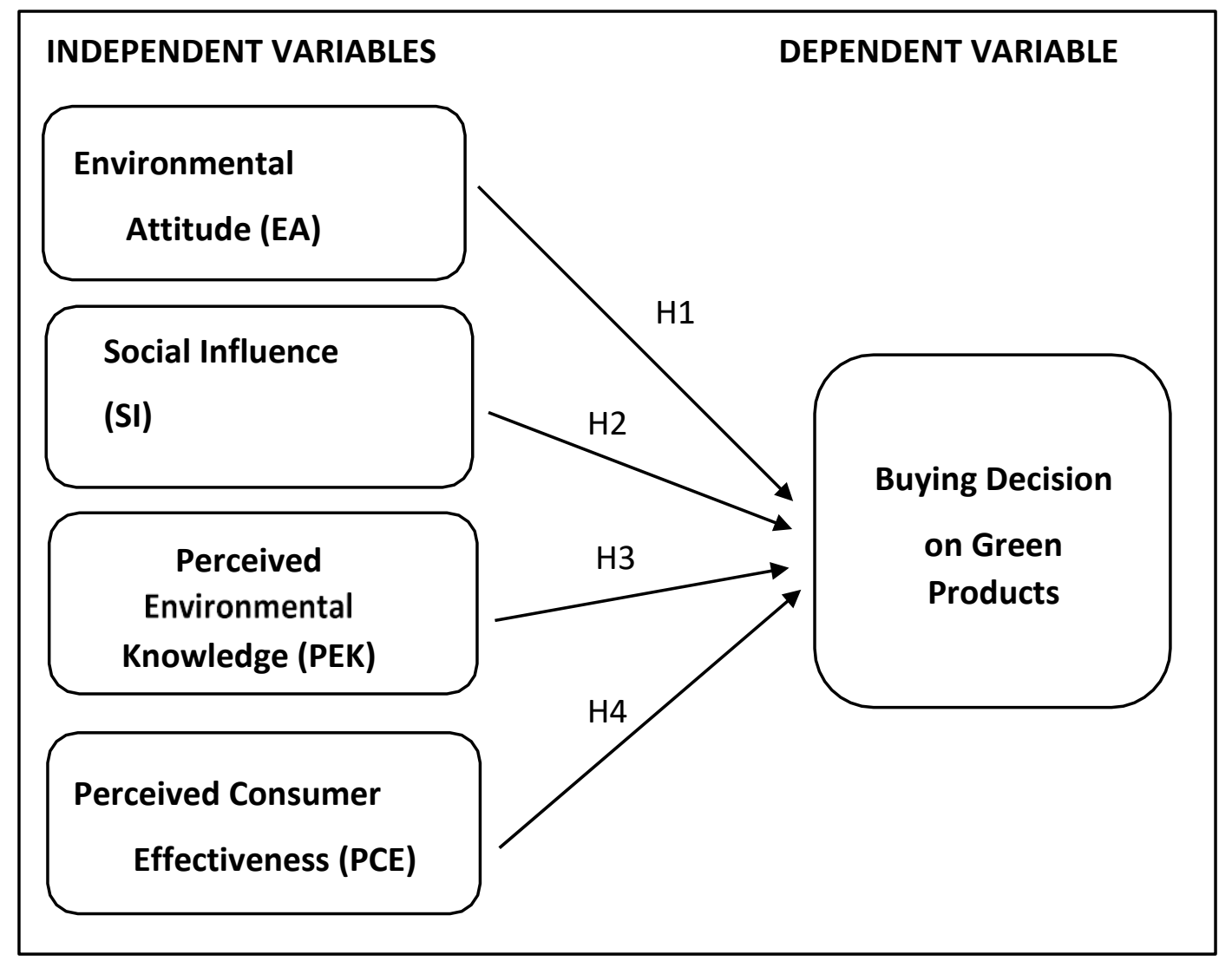

$\mathrm{H} 1$ : There is a positive relationship between EA and GPB H2: There is a positive relationship between SI and GPB. H3: There is a positive relationship between PEK and GPB. H4: There is a positive relationship between PCE and GPB.

\section{Research Methodology}

In this study, researcher conducted primary and secondary data to gather the appropriate information for this research study. Primary data was carried out to test hypothesis and the data was collected through survey. From this study, the target population are Malaysia's youth aged between 18- 30 years old (Madahi, \& Sukati, 2012). This segment of respondents targeted is due to the reason that the young generation nowadays are preferring to purchase environmentally friendly products and they had more environmental knowledge at the same time. Moreover, these respondents are considered to be potential consumers who 
interested in purchasing green products which they had positive point of view towards environment. At the same time, 15- 30 years old was considered as youths (Yunus \& Landau, 2019). However, the youth who aged 18 years old only had purchasing power, so the target population start from 18 years old to 30 years old. This able to evaluate the behaviour that affecting youth in make purchasing of green products accurately.

The sampling location carried out in this research is Klang Valley where the questionnaires were distributed. This is because Klang Valley occupied large number of potential consumers. The main targeted respondents are the young green consumers in Klang Valley to investigate the factors that influencing Malaysia's young generation in making green purchase decision. Apart from that, some of the questionnaires were distributed among respondents through online to make sure they can receive faster and easier.

This study was carrying out (Krejcie and Morgan, 1970) table to determine the sample size from a given population. According to Krejcie and Morgan (1970), there are 394 sets of questionnaires had allocated to the target respondents in Malaysia. The population of Malaysia in 2020 was estimated is $\mathbf{3 2 . 7}$ million (Current Population Estimates, Malaysia, $2020,2020)$. This research study had ensured the rule of thumb when deciding the sample size level. The primary data in this study was collected through self- administrated questionnaire in the short period of time.

\section{Data Analysis \\ Descriptive Statistic}

Table 4.1 : Descriptive Statistic

\begin{tabular}{ccc}
\hline Variables & Mean & Standard Deviation \\
\hline GPB & 4.6482 & 0.62224 \\
\hline EA & 4.1717 & 0.85843 \\
\hline SI & 4.4569 & 0.73838 \\
\hline PEK & 4.3772 & 0.75388 \\
\hline PCE & 4.4308 & 0.79186 \\
\hline
\end{tabular}

Source: Developed for the research

The table 4.1 above indicated that the mean of GPB is the highest with 4.6482 , however EA is the lowest mean among the variables with 4.1717. Otherwise, the results of standard deviation show that EA had the highest value with 0.85843 while the lowest value is GPB with 0.62224 .

\section{Respondent Demographic Profile}

Demographic profile of the respondents had been determined in Section A of the questionnaire. There are six questions were asked in the questionnaire including gender, age, ethnicity, monthly income, education and occupational level

According to the Table 4.2, it shows that majority of the respondents are female where 237 respondents that represented $60.20 \%$ out of the total 394 respondents, while there are 157 respondents are male participated in this survey which represented $39.80 \%$. Followed by the age group, there are 70 respondents $(17.80 \%)$ aged $18-20$ years old which is the lowest, however the highest respondents aged $27-30$ years old is 131 respondents (33.20\%). This 
show that undeniable there are majority of youths had high purchasing power who aged between 27-30 years old. Other than that, it describes the ethnicity group in Malaysia. Chinese is the majority respondents which consists of $46.40 \%$ (183 respondents) almost reached $50 \%$ of total respondents in this study, follow by Indian with $29.40 \%$ (116 respondents) out of 394 respondents. Based on the table 4.2, it shows that 163 respondents that representing $41.40 \%$ are Bachelor of Degree holders, while only less than $10 \%$ of respondents are Pre-University holders where 14 respondents that representing $3.60 \%$. In this study, Bachelor of Degree occupied the most among the other education level.

The data also indicate that the proportion of respondents with monthly income between $\mathrm{RM} 2,500$ and below consists of $42.60 \%$ (168 respondents) which is the highest, whereas about $13.70 \%$ (54 respondents) with monthly income between RM10,960 and above is the lowest. In addition, according to classification of households, it justified that RM2,500 and below is under the category of B40 yet RM10,960 and above is under category of T20. Finally, the results show the highest of occupational level is employee where 173 respondents (43.90\%) follow by housewife consists of 9 respondents $(2.30 \%)$ which is the lowest. Almost $50 \%$ of respondents are employees which are half of the total respondents in this survey.

Table 4.2: Demographic Profile of Respondents

\begin{tabular}{lcc}
\hline Category & Frequency (N) & Percentage (\%) \\
\hline Gender & & \\
\hline Male & 157 & $39.8 \%$ \\
\hline Female & 237 & $60.2 \%$ \\
\hline
\end{tabular}

\begin{tabular}{lcc}
\hline Age & & \\
\hline $18-20$ years old & 70 & $17.8 \%$ \\
\hline $21-23$ years old & 93 & $23.6 \%$ \\
\hline $24-26$ years old & 100 & $25.6 \%$ \\
\hline $27-30$ years old & 131 & $33.2 \%$ \\
\hline
\end{tabular}

\begin{tabular}{lcc}
\hline Ethnicity & & \\
\hline Malay & 92 & $23.4 \%$ \\
\hline Chinese & 183 & $46.4 \%$ \\
\hline Indian & 116 & $29.4 \%$ \\
\hline Others & 3 & $0.8 \%$ \\
\hline
\end{tabular}

\begin{tabular}{lll}
\hline Education Level & & \\
\hline Secondary School & 31 & $7.9 \%$ \\
\hline Pre-University & 14 & $3.6 \%$ \\
\hline
\end{tabular}


INTERNATIONAL JOURNAL OF ACADEMIC RESEARCH IN BUSINESS AND SOCIAL SCIENCES Vol. 12, No. 1, 2022, E-ISSN: 2222-6990 @ 2022 HRMARS

\begin{tabular}{lll}
\hline Diploma & 46 & $11.7 \%$ \\
\hline Bachelor of Degree & 163 & $41.4 \%$ \\
\hline Master of Degree & 124 & $31.5 \%$ \\
\hline Doctorate of Degree & 16 & $4.1 \%$ \\
\hline Monthly Income & & \\
\hline RM2,500 and below & 168 & $42.6 \%$ \\
\hline RM2,501-RM4,849 & 58 & $14.7 \%$ \\
\hline RM4,850-RM10,959 & 114 & $28.9 \%$ \\
\hline RM10,960 and above & 54 & $13.7 \%$ \\
\hline
\end{tabular}

\begin{tabular}{|c|c|c|}
\hline \multicolumn{3}{|c|}{ Occupational Level } \\
\hline Student & 144 & $36.5 \%$ \\
\hline Employee & 173 & $43.9 \%$ \\
\hline Housewife & 9 & $2.3 \%$ \\
\hline Self-employed & 68 & $17.3 \%$ \\
\hline
\end{tabular}

\section{Reliability Test}

Table 4.3: Reliability Test

\begin{tabular}{llc}
\hline Variables & & Cronbach's Alpha \\
\hline $\begin{array}{l}\text { Dependent } \\
\text { Variable }\end{array}$ & GPB & 0.877 \\
\hline $\begin{array}{lll}\text { Independent } \\
\text { Variables }\end{array}$ & EA & 0.924 \\
\cline { 2 - 3 } & SI & 0.919 \\
\cline { 2 - 3 } & PEK & 0.892 \\
\hline & PCE & 0.889 \\
\hline
\end{tabular}

Based on the results from table 4.3 , it had revealed that reliability of each variables is between 0.877 and 0.924 . Zikmund et al. (2009) explained that when the coefficient alpha was below 0.6, it considered as poor reliability. If the coefficient alpha between 0.60 and 0.70 , it will be a fair reliability. However, the coefficient alpha between 0.70 and 0.80 , it indicated as good reliability. In the meantime, if the range of coefficient alpha from 0.80 to 1.0 , it is a very good reliability. From the table above, Cronbach's Alpha of this study revealed that the EA is the highest coefficient with 0.924 whereas the lowest coefficient is GPB with 0.877 . 


\section{Pearson Correlation Analysis}

Table 4.4: Pearson Summary

\begin{tabular}{|c|c|c|}
\hline \multirow{2}{*}{ Variables } & \multicolumn{2}{|c|}{ GPB } \\
\hline & $r$ & P-value \\
\hline$\overline{E A}$ & $0.726 * *$ & $<0.001$ \\
\hline SI & $0.812 * *$ & $<0.001$ \\
\hline$\overline{\text { PEK }}$ & $0.865^{* *}$ & $<0.001$ \\
\hline$\overline{\text { PCE }}$ & $0.785^{* *}$ & $<0.001$ \\
\hline
\end{tabular}

According to the Table 4.4, it results that all the variables are positive correlations without any negative sign. Furthermore, these variables ranged between +0.71 to +0.90 which have high positive correlation. Meanwhile, the correlation of the independent variables are significant at the 0.01 level. Hence, the results shown that there is a significant relationship between dependent variables and independent variables in this research study.

\section{Multiple Regressions Analysis}

Table 4.5: Multiple Regression Analysis

\begin{tabular}{lc}
\hline Independent Variables & Dependent Variables (GPB) \\
\hline EA & $0.107^{*}$ \\
\hline SI & $0.213^{* * *}$ \\
\hline PEK & $0.521^{* * *}$ \\
\hline PCE & $0.156^{* *}$ \\
\hline $\mathbf{R}^{\mathbf{2}}$ & 0.792 \\
\hline Adjusted $\mathbf{R}^{\mathbf{2}}$ & 0.790 \\
\hline F-value & $370.818^{* * *}$ \\
\hline
\end{tabular}

${ }^{*} p<0.05 ; * * p<0.01 ; * * * p<0.001$ Source: Developed for the research

Based on the results from table 4.5, it explains that the total variance of the whole model was $79.20 \%$, F-test is $370.818, p<0.001$. This variance shows that the regression model predicted the relationship between thefour independent variables and dependent variable. Besides, the adjusted $R^{2}$ is 0.790 which indicated that there is about $79 \%$ of the variations in GPB were affected by the factors above. According to the model, the highest beta value is PEK with beta $=0.521, * * * p<0.001$, meanwhile EA is the lowest beta value with beta $=0.107,{ }^{*} p<0.05$.

\section{Discussion}

H1: There is a positive relationship between EA and behaviour to purchase green products.

Based on the results shown there is a positive relationship between youths' EA and behaviour to purchase green products. According to this research, the finding is reliable with 
Chen and Chai (2010) which concluded that EA is the attention to the environment is rooted in personal concept and the degree to which individual seen it as a part of the natural environment. Besides, attitude also represent what the consumers' product purchase decisions which usually based on EAs. This explained that attitude was affecting the willingness of consumers purchase green products. Therefore, young consumers can make some contribution to improve the quality of environmental by purchasing green products such as products with recyclable packaging or products with proper disposal of nonbiodegradable waste (Sevrek \& Gu, 2017). In order to promote the sustainable consumption habits of Malaysians, the government has issued various strategies to carry out the sustainable consumption and development. Hence, this clearly shown that EA is directly influencing GPB among young generation.

H2: There is a positive relationship between $\mathrm{SI}$ and behaviour to purchase green products.

According to the table 5.1, it results that the SI had positive relationship with behaviour to purchase green products. Dagher and Itani (2012) explained that the respondents almost know about the green products and environmental issues from friends or social media. This results of study was consistent with Sevrek and Gu (2017) due to there are positive relationship between SI and GPB. SI can be observed at peer pressure, standard compliant and other factors. This research was conducted in Lebanon to investigate the impact of SI on GPB. SI was observed at peer pressure, standard compliant and other factors. Besides, GPB can be influenced by SI through the social media such as email, blog, Instagram, Twitter, Facebook and YouTube. This revealed that green consumption is strongly influenced by associations and encouraging reference groups. Thus, there had strong evidence justified that SI was directly affecting GPB.

H3: There is a positive relationship between PEK and behaviour to purchase green products.

The results of research outcome indicated that there is a positive relationship between PEK and behaviour to purchase green products. This is reliable with the previous research study by Liobikienè, et al (2016), which conducted in Europe Union. Based on the study, people always believed that knowledge of environmental is the motivation or encouragement for GPB. Furthermore, environmental knowledge able to help consumers to aware and protect environmental issues. Environmental information able to guide consumers by pointing out the green products among other equivalent products and young consumers will behave more green behaviours. Hence, those consumers who had knowledge about environmental problems and the use of green products may also have more optimistic attitude towards green products. In short, PEK is positive influencing young generation's behaviour to purchase green products.

H4: There is a positive relationship between PCE and behaviour to purchase green products.

From the results on table 5.1, PCE had positive relationship with behaviour to purchase green products. Kim and Choi (2005) justified that PCE was determined through knowledge and experiences as well as changing according to personal knowledge and experience. It had been found that PCE refer to self-evaluation of problem, which is different from reflecting the attitudes toward problem evaluation. Moreover, young consumers' worries regarding 
environmental problems might not transform quickly into GPB. However, people who believe that their environmentally friendly actions will bring positive impact are more likely to engage in this behaviour to help environmental problems. Thus, the results shown that it is consistent with Kim and Choi (2005) which indicated that students of Caucasia believe their actions and attitudes able to protect the environmental through purchasing green products. Lastly, it concluded that there is a positive relationship between PCE and GPB.

This study shows that the factors EA has a positive relationship with GPB. Tan (2011) explained that the perspectives of GPB from consumers is important for public and themselves which will affect their willingness to purchase for green products. Meanwhile, it is important that consumers' confidence will influence their GPB. For example, government are suggested to promote the sustainable consumption practices to the public through social media and campaign. This able to educate and strengthen environmental awareness and attention among the youths very fast. Government also encouraged to collaborate with marketers to raise green marketing to improve consumers' confidence on green purchase. Besides, marketers also should participated more Corporate Social Responsibility activities to support green purchase for their business.

Additionally, SI also had directly positive relationship with GPB among young generation. Word of mouth is a communication tool that will influence GPB. Nguyen et.al (2018) revealed that marketers can conduct green marketing activities by targeting friends and families to influence the young consumers. For instance, marketers should consider launching campaign to encourage young consumers to practice GPB especially future generation. Promoters of green products also encouraged to recommend the young consumers to purchase more green products (Lian \& Yoong, 2019). A clear and honest information about green products also should be provided to young consumers. Hence, consumers able to suggest for their friends andfamilies.

Furthermore, there is positive relationship between PEK and GPB. Environmental knowledge of consumers is important to supply chains and retailers, because environmental problems can affect purchasing of green products. Thus, marketers able to target right market segment after understanding green consumers (Lian \& Yoong, 2019). For example, marketers can launch innovative products with green and functional attributes. Retailers also encouraged to providing points-of purchase display by facilitate a convenient shopping environment. Other than that, government should make sure the information of eco-label on the products is honest. Clear information would improve consumers' knowledge by enhance their trust in green products (Noor et. al., 2012).

Lastly, this research stated that PCE had positive relationship with GPB. Government must let young consumers to know and understand environmental protection is their responsibilities as a public. The benefits of green purchasing should be remembered and keep in their mind-set so that they had a thought about green purchase able to minimize environmental and natural resources damage. For example, environmental education should be provided to young consumers on what is green products. Besides, marketers also encouraged to display green products at the store front that easy to notice by the consumers (Joshi \& Rahman, 2015). 


\section{Conclusion}

In brief, the objective of this study research is to investigate the factors that influence young generation's GPB in Malaysia. This study indicated that youths have positive behaviour towards purchasing green products. There are few limitations mentioned had been identified and pointed out for researchers to improve in the future study. First, the limitation of this study is demographic bias. Researcher distributes survey questions to youths at Klang Valley. Every respondent has different view and attitude towards behaviour to purchase green products. However, researchers only concentrate on youth aged between 18 and 30 years old. Since different age groups may have different understandings of green products, thus their attitudes towards green products also will be different. For instance, due to young generation have more knowledge about environmental protection, hence they are more likely to buy green products. In other words, most of the old generation lack of knowledge about environmental issues and green products, this caused them to prefer to buy conventional products.

To make sure the data and results more accurate and reliable, future researchers was recommended to target all age groups of young and old respondents. The number of respondents that representing each of the age group should be consistent. This is due to the reason that people with different ages have different views towards this study topic. Hence, researchers can gain deeper understanding on respondents' attitudes towards environmental and green products. At the same time, future researchers were suggested to conduct this survey among all ethnicity and age group consistently to enable the findings to become more comprehensive.

It can be the guidelines for other researchers to determine factors that influence Malaysia's young generation in making green purchase decisions. Therefore, it helps to build young people's awareness of green products and environmental awareness.

\section{References}

Chen, T. B., \& Chai, L. T. (2010). Attitude towards the environment and green products: Consumers' perspective. Management science and engineering, 4(2), 27-39.

Chong, C. H., Tan, W. X., Ting, Z. J., Liu, P., Ma, L., Li, Z., \& Ni, W. (2019). The driving factors of energy-related $\mathrm{CO} 2$ emission growth in Malaysia: The LMDI decomposition method based on energy allocation analysis. Renewable and Sustainable Energy Reviews, $115,109356$.

Dagher, G. K., \& Itani, O. (2014). Factors influencing green purchasing behaviour: Empirical evidence from the Lebanese consumers. Journal of Consumer Behaviour, 13(3), 188195.

Dagher, G., \& Itani, O. (2012). The influence of environmental attitude, environmental concern and social influence on green purchasing behavior. Review of Business Research, 12(2), 104-111.

Jaiswal, D., \& Kant, R. (2018). Green purchasing behaviour: A conceptual framework and empirical investigation of Indian consumers. Journal of Retailing and Consumer Services, 41, 60-69.

Joshi, Y., \& Rahman, Z. (2015). Factors affecting green purchase behaviour and future research directions. International Strategic management review,3(1- 2), 128-143.

Kadir, J. M. A., Hassan, N. N. N. M., \& Abd Aziz, N. N. (2018). Investigating Students' Attitude and Intention to Use Biodegradable Drinking Straw in Emerging Country. 
Kim, Y., \& Choi, S. M. (2005). Antecedents of green purchase behavior: An examination of collectivism, environmental concern, and PCE. ACR North American Advances.

Krejcie, R. V., \& Morgan, D. W. (1970). Determining sample size for research activities. Educational and psychological measurement, 30(3), 607-610.

Lian, S. B., \& Yoong, L. C. (2019). Assessing the young consumer' moves and purchase behavior for organic food: An empirical evidence from a developing nation. International Journal of Academic Research in Business and Society, 9(1), pp 69- 87.

Liobikienè, G., Mandravickaitè, J., \& Bernatonienè, J. (2016). Theory of planned behavior approach to understand the green purchasing behavior in the EU: A cross-cultural study. Ecological Economics, 125, 38-46.

Madahi, A., \& Sukati, I. (2012). The effect of external factors on purchase intention amongst young generation in Malaysia. International Business Research, 5(8), 153.

Mostafa, M. M. (2007). Gender differences in Egyptian consumers' green purchase behaviour: the effects of environmental knowledge, concern and attitude. International Journal of Consumer Studies, 31(3), 220-229.

Noor, N. A. M., Muhammad, A., Kassim, A., Jamil, C. Z. M., Mat, N., Mat, N., \& Salleh, H. S. (2012). Creating green consumers: how environmental knowledge and environmental attitude lead to green purchase behaviour?. International Journal of Arts \& Sciences, 5(1), 55.

Nguyen, T. N., Lobo, A., \& Nguyen, B. K. (2018). Young consumers' green purchase behaviour in an emerging market. Journal of Strategic Marketing, 26(7), 583-600.

Rezai, G., Teng, P. K., Mohamed, Z., \& Shamsudin, M. N. (2013). Is it easy to go green? Consumer perception and green concept. American journal of applied sciences, 10(8), 793-800.

Seyrek, I. H., \& Gu, M. (2017). Factors affecting green purchasing behavior: A study of Turkish consumers. International Journal of Academic Research in Business and Society, 7(1), pp 306-319.

Uddin, S. F., \& Khan, M. N. (2016). Green purchasing behaviour of young Indian consumers: An exploratory study. Global Business Review, 17(6), 1469- 1479.

Yadav, R., \& Pathak, G. S. (2017). Determinants of consumers' green purchase behavior in a developing nation: Applying and extending the theory of planned behavior. Ecological economics, 134, 114-122.

Varshneya, G., Pandey, S. K., \& Das, G. (2017). Impact of social influence and green consumption values on purchase intention of organic clothing: a study on collectivist developing economy. Global Business Review, 18(2), 478- 492.

Hessami, Z. H., \& Yousefi, P. (2013). Investigation of major factors influencing green purchasing behavior: Interactive approach. European Online Journal of Natural and Social Sciences, 2(4), pp-584. 